\title{
Performance social corporativa: Análise da dimensão da estrutura do trabalho unidades produtivas de cotonicultura
}

\section{Corporate Social Performance: Analysis of the size of the structure of production units work of cotton farming.}

\author{
Fernanda Pereira Silva ${ }^{1}$, Lucia Santana de Freitas ${ }^{2}$, Dércio Braga Santos ${ }^{3}$
}

\begin{abstract}
Resumo: A Performance Social Corporativa (PSC) ocorre por meio da mensuração das práticas de Responsabilidade Social Corporativa (RSC) e transmitidas pelos valores sociais e ambientais, além dos valores econômicos e legais. Para isso, o objetivo do presente trabalho idealizou-se em analisar a PSC, a partir da dimensão estrutura de trabalho de duas unidades produtivas (UP’s) de cotonicultura, denominadas de UP1 e UP2, situadas no Mato Grosso - Brasil, a luz do método triangulação de dados. Por conseguinte, o estudo focou-se nas abordagens quanti-qualitativa, conduzidas pelos métodos exploratórios e descritivos, sob as percepções dos gestores e colaboradores, tendo em vista a aplicação do método de triangulação dos dados, primários, secundários, bem como as inferências dos pesquisadores, derivadas dos questionários de perguntas objetivas e subjetivas. Logo, os resultados médios das médias $\left(\overline{\bar{x}}_{i}\right)$ da PSC da dimensão estrutura de trabalho das UP's apresentam boas performances (B), contudo, com altos níveis de representatividades nas respostas dos pesquisados, dadas as correspondências regulares das médias $\left(\overline{\bar{x}}_{i}\right)$. Em relação aos parâmetros alimentação e acomodação representaram boas performances, no entanto com regulares e boas representatividades nas médias das respostas dos pesquisados. Por fim, os parâmetros de qualidade do trabalho apresentaram regulares e boas performances, respectivamente e no parâmetro participação nas decisões de trabalho apontaram nas UP’s, boas e regulares performances, respectivamente.
\end{abstract}

Palavras-chave: Peformance Social Corporativa; Responsabilidade Social Corporativa; Produção de Algodão.

Abstract: The Social Performance Corporate (PSC) is through the measurement of CSR practices (CSR) and transmitted by social and environmental values, beyond economic and legal values. For this, the objective of this work was devised to analyze the PSC, from the size working structure of two production units (UP's) of cotton production, called UP1 and UP2, located in Mato Grosso - Brazil, the light method triangulation data. Therefore, the study focused on approaches quantitative and qualitative, conducted by exploratory and descriptive methods, in the perceptions of managers and employees, with a view to application of the data triangulation method, primary, secondary, and the implications of researchers, derived from questionnaires of objective and subjective questions. Thus, the average results of averages ( $\overline{\bar{x}}_{\mathrm{i}}$ ) of PSC dimension working structure of UP's have good performances (B), however, with high levels of representativity in the answers of respondents, given the regular correspondence of means $\left(\overline{\bar{x}}_{\mathrm{i}}\right)$ Regarding food and accommodation parameters represented good performances, however with regular and good representativeness in the average response of respondents. Finally, the work quality parameters showed regular and good performances, respectively and parameter participation in work decisions aimed at UP's, good and regular performances, respectively.

Keywords: Corporate Social Performance; Corporate social responsibility; Cotton Production.

\footnotetext{
*Autor para correspondência

Recebido para publicação em 07/10/2015; aprovado em 20/12/2015

${ }^{1}$ Doutoranda do Programa de Pós-graduação em Recursos Naturais - PPGRN/UFCG; Docente Mestre em Administração da Universidade Federal de Mato Grosso - UFMT, campus de Rondonópolis; Rondonópolis, MT; Fone (066) 3410-4070; admfernandas@ yahoo.com.br

${ }^{2}$ Docente Doutora Associada do Curso de Administração da Universidade Federal de Campina Grande e professora do Programa de Doutorado em Recursos Naturais - PPGRN; Fone: (083) 2101-1651; lucia.sdefreitas@gmail.com

${ }^{3}$ Docente Doutor Adjunto 3 do Departamento de Matemática da Universidade Federal de Mato Grosso, Campus de Rondónopolis; Fone (066)-3410-4057; derciobraga@yahoo.com.br
} 


\section{INTRODUÇÃO}

A cotonicultura de acordo com a Associação Matogrossense dos Produtores de Algodão - AMPA (2014), vem ganhando destaque na produção de algodão, desde o final da década de 1990, devido as perspectivas econômicas, que no ano de 2013/2014, representou, o primeiro, em volume de grãos, perfazendo um total de $50 \%$, com $96,8 \%$, de área plantada e um crescimento de $28,5 \%$, por conseguinte, o volume do algodão em pluma, representou o terceiro maior exportador do produto (IMEA, 2014). Estes resultados, segundo a Associação Brasileira dos Produtores do Algodão ABRAPA (2014) se devem, por causa êxito da agricultura comercial e a adequação da produção regional, em face das exigências e as dinâmicas capitalistas integradas pelos mercados nacionais e internacionais, tais como: o aumento da produtividade; as condições ambientais para produção de algodão, dentre elas a qualidade do solo, da água e do clima, propiciando assim, maior produtividade; a resistência do algodão à seca e às regiões semiáridas; as alternativas para reter a população no meio rural e a geração do emprego e renda.

Concomitante a isto, os órgãos regulamentadores do algodão, em especial, a Associação Brasileira dos Produtores de Algodão - ABRAPA, a partir destes resultados, buscou métodos e técnicas para se aplicar nas práticas da cotonicultura, de modo impulsionaram o sistema produtivo mundial, justificadas pelo crescimento populacional, a produção em massa e o consumismo exacerbado. Além disso, buscam mecanismos de minimização dos impactos negativos que a atividade do algodão ocasiona aos stakeholders e ao meio biótico, causando desequilíbrios social e ambiental, muitas as vezes irreversíveis, em decorrência ao atendimento da produção em grandes escalas para atender o sistema econômico e a busca pela competitividade. De acordo com Mcguire (1963), a PSC exorta as corporações à assumirem a RSC frente aos stakeholders, estendendo-se além de suas obrigações econômicas e jurídicas.

No entanto, mesmo com grandes perspectivas econômicas o setor da cotonicultura necessitou de se adequar além da qualidade dos produtos e serviços, as questões sociais, ambientais, econômicas e legais, com a implementação de sistemas de indicadores para avaliar o desempenho da produção e a qualidade do algodão brasileiro, quanto aos princípios sociais, ambientais e econômicos. Em decorrência disto, este trabalho pretende-se avaliar alguns parâmetros através da Performance Social Corporativa (PSC) do setor, bem como as práticas de responsabilidade social corporativa (RSC), em face das exigências do mercado e dos diversos problemas socioambientais que atingem os stakeholders, quanto a qualidade dos serviços prestados nas unidades produtivas, bem como estratégias com responsabilidades corporativas para minimizarem os grandes impactos negativos corporativos. Por conseguinte, na visão de Davis e Blomstrom (1966), a RSC obriga as decisões sobre o sistema social inteiro, repercutindo assim, segundo Jacobi et al. (2007), nas mudanças comportamentais corporativas em decorrência dos impactos vinculados aos projetos, políticas e programas.

Neste sentido, o setor da cotonicultura aplica políticas e programas, para melhoria das práticas de responsabilidade corporativa através dos princípios para reforçar os desempenhos das fazendas (Unidades Produtivas - UP's). Estas políticas e programas de certificações visam maximizarem os impactos positivos e minimizarem os impactos negativos, para protegerem as demandas futuras do uso da matéria-prima, que é o alicerce que movimenta a produção e o consumo, com novas tecnologias, produtos com alto padrão de qualidade e valor agregado, equidade e justiça social aos stakeholders envolvidos. Para as corporações socialmente responsáveis, segundo World Business Council for Sustainable Development (1998), devem promover o desenvolvimento sustentável, a ecoeficiência, a inovação e a RSC, pode empreender no compromisso contínuo dos stakeholders para contribuir para o desenvolvimento econômico, melhorando a qualidade de vida dos trabalhadores, da comunidade e da sociedade em geral. Por conseguinte, essas ações colaboram para melhoria das ações econômicas, legais, morais ou filantrópicas das corporações, que influenciam e permitem melhorar a qualidade de vida dos stakeholders e da sociedade (HILL et al., 2006).

Estas práticas corporativas contribuem para melhoria da imagem interna e/ou externa e as minimizações das pressões impostas pelos mercados e stakeholders, visto que, as corporações têm o papel não apenas de jogadores passivos, mas, também, ativos na economia global e ainda recebem influência da sociedade em seu entorno (HUTCHINS E SUTHERLAND, 2008). De tal forma, os autores retrocitados, salientam que a RSC constitui-se dos aspectos sociais e de respeito ao meio ambiente, com a utilização dos sistemas de produção mais limpa; a responsabilidade econômica e social, considerando lucratividade e os stakeholders (clientes, fornecedores, funcionários, autoridades públicas e o público em geral), com fortes ligações entre os conceitos de sustentabilidade e RSC, que dessa forma, incluem-se os comportamentos éticos relacionados ao meio ambiente, à sociedade e à economia. Neste contexto, Dahlsrud (2005), trata a RSC pelas dimensões sociais, ambientais e econômicas, a partir de diferentes categorias de impactos corporativos.

Nessa condição, oportunizam em ações éticas e transparentes, para minimização dos impactos negativos no meio ambiente e na sociedade. Conforme defende Wood (2010), a PSC resulta das interações da organização corporativa com seu ambiente mais amplo, incluindo os desenvolvimentos social, cultural, legal, político e econômico, por meio das dimensões naturais, cujas capacidades de respostas sociais de RSC são dependentes das extensões dos processos corporativos internos dos gestores, onde estes processos se ajustam as mudanças e as expectativas sociais. Para análise do conjunto das atividades corporativas, Wood (1991) relaciona a PSC com base nas análises descritivas por categorizações, concentrando-se nos impactos e resultados dos stakeholders e da sociedade, bem como nos resultados gerais e específicos dos princípios estruturais de RSC e nos processos de responsividade social corporativa que definem resultados produzidos, monitorados, avaliados, compensados e retificados (ou não). Sob o ponto vista de Chen et al. (2008), esses processos se derivam das competências essenciais atribuídas pela consciência socioambiental dos colaboradores, advindos do aprendizado coletivo e das capacidades de inovação dos stakeholders.

Diante disso, o presente trabalho objetiva-se em analisar a PSC de duas unidades produtivas (UP's) de cotonicultura, 
denominadas de UP1 e UP2, a partir da dimensão e parâmetros da estrutura de trabalho, situadas no Mato Grosso - Brasil, bem como a luz do método triangulação de dados.

\section{MATERIAL E MÉTODOS}

O presente trabalho baseou-se no método descritivo e exploratório, dada a abordagem qualitativa e quantitativa, através do estudo de caso aplicados aos gestores e colaboradores de unidades produtivas de cotonicultura do Estado de Mato Grosso. Com isto, baseou-se na amostra por intencionalidade dos dados secundários do Estado de Mato Grosso, disponibilizados pelo Instituto Brasileiro de Geografia e Estatística, IBGE (2015), mais especificamente pelo Banco de Dados Agregados do Sistema IBGE de Recuperação Automática - SIDRA, sendo estes dados destacados a partir dos produtores com níveis "médios", cujas grandezas concentram-se nas áreas produtivas de algodão entre 10.000 a 20.000 e pelo desígnio geográfico, as unidades produtivas - UP's, localizadas no Estado de Mato Grosso, restringindo-se à 4 (quatro) na região norte; 2 (duas) região nordeste e 3 (três) na região sudeste, perfazendo assim, o universo de pesquisado constituir-se-á de 9 (nove) UP's, e com amostra fidedigna de 2 (duas) UP's de cotonicultura, à saber, unidades UP1 e UP2, situadas, respectivamente, no sudoeste e no norte do estado, ambas com certificações ABR/BCI.

A amostra da pesquisa, na visão de Minayo (2002) propicia a abrangência da totalidade do problema investigado em suas múltiplas questões. Assim, os sujeitos de pesquisa, UP1 e UP2, destacaram-se uma população amostral de 500 (quinhentos) stakeholders diretos, sendo divididos na UP1 200 (duzentos) e na UP2 300 (trezentos) colaboradores e gestores. Por conseguinte, o universo amostral aleatório compreendeu-se a 82 (oitenta e dois) stakeholders diretos, correspondendo a $22 \%$ (vinte dois por cento) dos questionários aplicados. Contudo, na UP1, aplicou-se 21 (vinte e um) questionários aos colaboradores e 1 (um) ao gestor, totalizando 22 (vinte dois) questionários, enquanto na UP2, aplicou-se 58 (cinquenta e oito) questionários aos colaboradores e 2 (dois) aos gestores.

A aplicação da pesquisa nas duas UP's, baseou-se em dois casos de pesquisa, que segundo, Yin (2010) seu uso, permite replicação direta e conclusões analíticas independentes ou contrastantes, fortalecendo os achados de pesquisa. Posto isto, buscou-se a triangulação de dados para analisar os níveis de PSC da cotonicultura derivadas dos dados primários e secundários, bem como a inferência da pesquisadora, assim descritos. Os dados primários basearamse em questionários e entrevistas, estruturados com perguntas quantitativas (objetivas) e qualitativas (subjetivas), aplicados aos gestores do IAS e das UP's e aos colaboradores das UP's.

Outrossim, o método de triangulação de dados permite a validação dos resultados de pesquisa (COX e HASSARD, 2005). Seu uso possibilitou a avaliação dos dados primários, secundários e as inferências da pesquisadora, nas UP's, assim destacadas: o primeiro e o terceiro instrumento de pesquisa aplicou-se os questionários e entrevistas, aos gestores e colaboradores em geral nas UP's e o segundo buscou-se informações através dos sítios da internet sobre os órgãos regulamentadores do algodão, através dos selos de certificações. Assim, as estratégias de coletas dos dados caracterizaram-se com base nos dados primários, dados secundários e a inferência da pesquisadora, conforme esquema da Figura 1.

Figura 1. Triangulação de Dados para análise da Pesquisa

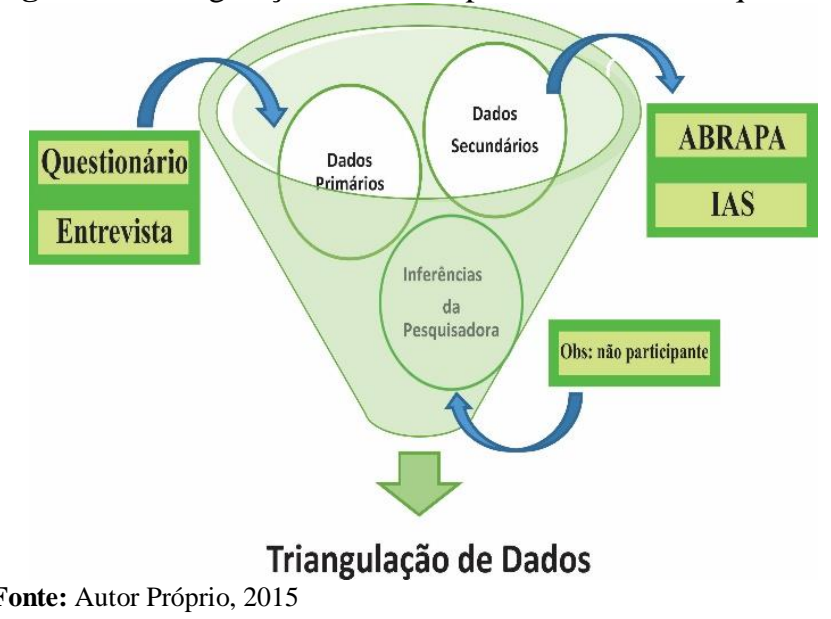

Com base nisto, a percepção de Denzin (1978) a triangulação metodológica, trata-se da triangulação entre métodos", que se utiliza das diversas técnicas dentro de um determinado método para coletar e interpretar dados.

Onde:

1) Dados primários: informações extraídas das unidades produtivas de cotonicultura.

2) Dados secundários: informações extraídas das bases de dados dos órgãos reguladores de cotonicultura, da Associação Brasileira de Produtores de Algodão - ABRAPA, Instituto do Algodão Social - IAS; Associação Matogrossense dos Produtores de Algodão - AMPA e Instituto Brasileiro de Geografia e Estatística - IBGE, a partir de elementos expostos nos sítios da internet, mais especificamente nos manuais, relatórios, normas e regulamentos.

3) Inferência da pesquisadora (observação não participante): consistiu-se da participação da pesquisadora in loco, de modo a extrair as informações das UP's de cotonicultura em consonância com sua percepção, de modo a aumentar a qualidade e veracidade das informações qualitativas e quantitativas.

Para análise metodológica dos níveis de PSC da cotonicultura, valeu-se da triangulação de dados que permite a validação dos resultados de pesquisa (COX; HASSARD, 2005). Na pesquisa buscou-se cruzar as fontes primários, secundários e as inferências dos pesquisadores, que nas visões de Duffy (1987); Mathison (1988) e Kelle (2001), a triangulação de métodos reforça as matrizes determinando o grau de convergência dos indicadores de validade dos resultados e da investigação, aumentado confiança e a legitimidade da pesquisa. Com isso, melhora a validação entre as variáveis de pesquisa para validade externa dos resultados e a validade dos construtos teóricos necessários à a análise. As combinações de técnicas, abordagens e conceitos ou linguagem de pesquisa, em um único estudo com as mesmas questões de pesquisa, Yin (2010) salienta que contribuem com evidências ricas às conduções das análises. Uma vez, que Azevedo et al., (2013), reforça que ao plicar em um mesmo fenômeno de pesquisa com mais de uma fonte de dados de diferentes ângulos, permite corroborar, elaborar ou iluminar o problema de pesquisa, limitando-se os vieses pessoais e metodológicos, aumentando a generalização de um estudo. 
Assim, as estratégias de tratamentos dos resultados de PSC, através das dimensões e parâmetros da estrutura de trabalho, basearam-se em três etapas, são elas: 1) Escalas de Likert; 2) nível de performance a partir dos comportamentos e respostas de Carroll (1979) e 3) Performance categorizada pelos princípios de PSC, cujas estruturações seguem os seguintes passos em conformidade com o Quadro 1.

Quadro 1. Análise da dimensão de PSC - Estrutura de trabalho

\begin{tabular}{|c|c|c|c|c|c|}
\hline \multicolumn{6}{|c|}{ Análise das dimensões e parâmetros de PSC da cotonicultura - Dimensão Estrutura do Trabalho } \\
\hline \multirow{4}{*}{$\begin{array}{l}\text { Níveis de PSC } \\
\text { comportamen } \\
\text { tos das escalas de } \\
\text { Likert }\end{array}$} & 1 & 2 & $\mathbf{3}$ & 4 & $\mathbf{5}$ \\
\hline & Crítica & Suportável & Regular & Boa & Ótima \\
\hline & $0,00 \vdash 0,20$ & $0,20 \vdash 0,40$ & $0,40 \vdash 0,60$ & $0,60 \vdash 0,80$ & $0,80 \vdash 1,00$ \\
\hline & $\begin{array}{l}\text { Desempenho } \\
\text { prejudicial e } \\
\text { ameaçador aos } \\
\text { objetivos } \\
\text { corporativos }\end{array}$ & $\begin{array}{l}\text { Desempenho } \\
\text { funcional marcado } \\
\text { aos objetivos } \\
\text { corporativos }\end{array}$ & $\begin{array}{l}\text { Desempenho } \\
\text { defensivo } \\
\text { (proteção) aos } \\
\text { objetivos } \\
\text { corporativos }\end{array}$ & $\begin{array}{c}\text { Desempenho } \\
\text { adaptativo aos } \\
\text { objetivos } \\
\text { corporativos, } \\
\text { exigências legais } \\
\text { e tecnológicas }\end{array}$ & $\begin{array}{l}\text { Desempenho de } \\
\text { excelência à } \\
\text { conquista dos } \\
\text { objetivos } \\
\text { corporativos, além } \\
\text { das expectativas. }\end{array}$ \\
\hline \multicolumn{6}{|c|}{ Nível de PSC de Comportamento e Resposta } \\
\hline $\begin{array}{c}\text { Situações de } \\
\text { Performances }\end{array}$ & Reativa & Defensiva & Acomodativa & Proativa & $\begin{array}{c}\text { Situação de } \\
\text { Performance } \\
\end{array}$ \\
\hline $\begin{array}{c}\text { Variáveis de } \\
\text { Análises } \\
\end{array}$ & $0,00 \vdash 0,25$ & $0,25 \vdash 0,50$ & $0,50 \vdash 0,75$ & $0,75 \vdash 1,00$ & Variáveis de Análise \\
\hline $\begin{array}{c}\text { Níveis de PSC } \\
\text { - Comportamen } \\
\text { to (CARROLL, } \\
\text { 1979) } \\
\text { (Qualitativa) }\end{array}$ & $\begin{array}{l}\text { Comportamento } \\
\text { prejudicial } \\
\text { ameaçador aos } \\
\text { objetivos } \\
\text { corporativos }\end{array}$ & $\begin{array}{c}\text { Comportamento } \\
\text { defensivo (proteção) } \\
\text { aos objetivos } \\
\text { corporativos }\end{array}$ & $\begin{array}{c}\text { Comportamento } \\
\text { adaptativo aos } \\
\text { objetivos } \\
\text { corporativos, } \\
\text { exigências legais e } \\
\text { tecnológicas }\end{array}$ & $\begin{array}{c}\text { Comporta } \\
\text { mento de } \\
\text { excelência à } \\
\text { conquista dos } \\
\text { objetivos } \\
\text { corporativos, } \\
\text { além das } \\
\text { expectativas. }\end{array}$ & $\begin{array}{c}\text { Nível de PSC } \\
\text { Comporta } \\
\text { mento (CARROLL, } \\
\text { 1979) } \\
\text { (Qualitativa) }\end{array}$ \\
\hline
\end{tabular}

Fonte: Autor Próprio, 2015

Para análise dos resultados empregou-se as medidas de posição central, dando a tratativa em torno da média aritmética para dados agrupados, cuja sentença matemática é dada pela equação 01 .

$$
\bar{x}=\sum_{i=1}^{k} x_{i} f_{i}
$$

Onde:

$x_{i}=$ parâmetros de questões de PSC e $f_{i}=$ frequência ou quantidades de afirmações dos entrevistados, com $i=1, \ldots, k$-ésimo parâmetro de questão de PSC.

Além disso, empregou-se os usos das medidas de dispersões sobre os dados amostrais, como: desvio-padrão amostral (s) e os coeficientes de variações (CV), dados, respectivamente, pelas equações 02 e 03 .

$$
\begin{aligned}
& s=\sqrt{s^{2}} \text { e } C V=\frac{s}{\bar{x}} \\
& \text { Onde: } \\
& s^{2} \text { é a variância amostral } \\
& s^{2}=\frac{\sum_{i=1}^{k}\left(\bar{x}-x_{i}\right) f_{i}}{n-1} .
\end{aligned}
$$

Para análise dos dados, deste trabalho, seguem-se as faixas de variabilidade do desvio-padrão, conforme Quadro 2.

As classificações de PSC de acordo com as distribuições dos níveis de representatividades das dimensões e parâmetros seguem-se conforme Quadro 3.

Quadro 2. Variação e classificação de PSC a partir do desvio Padrão de $(s)$

\begin{tabular}{|c|c|}
\hline Variação do Desvio-Padrão & Nível de Dispersão dos dados (parâmetros) em relação à média \\
\hline $\mathbf{0} \leq \boldsymbol{s}<\mathbf{0 , 1 5}$ & baixa dispersão dos dados em relação à média \\
\hline $\mathbf{0} \leq \boldsymbol{s}<\mathbf{0 , 1 5}$ & média dispersão dos dados em relação à média \\
\hline $\boldsymbol{s} \geq \mathbf{0 , 3 0}$ & alta dispersão dos dados em relação à média \\
\hline
\end{tabular}

Fonte: elaborado a partir de Martins e Domingues, 2014.

Quadro 3. Índice de Análise de PSC a partir do Coeficiente de Variação (CV) para representatividade da média

\begin{tabular}{|c|c|l|}
\hline Variação do CV & Nível de Variabilidade & \multicolumn{1}{|c|}{ Análise de Representatividade da Média $(\overline{\mathbf{x}})$} \\
\hline $\mathbf{C V}<\mathbf{0 , 1}$ & Baixa variabilidade $(\mathrm{B})$ & $\begin{array}{l}\text { Excelente representatividade para média aritmética }(\overline{\mathrm{x}}) \\
\text { como medida de posição. }\end{array}$ \\
\hline $\mathbf{0}, \mathbf{1} \leq \mathbf{C V}<\mathbf{0 , 2}$ & Média variabilidade $(\mathrm{M})$ & $\begin{array}{l}\text { Boa representatividade para média aritmética }(\overline{\mathrm{x}}) \text { como } \\
\text { medida de posição. }\end{array}$ \\
\hline $\mathbf{0 , 2} \leq \mathbf{C V}<\mathbf{0 , 3}$ & Alta variabilidade $(\mathrm{A})$ & $\begin{array}{l}\text { Regular representatividade para média aritmética }(\overline{\mathrm{x}}) \text { como } \\
\text { medida de posição. }\end{array}$ \\
\hline $\mathbf{C V} \geq \mathbf{0 , 3}$ & Muito alta variabilidade $(\mathrm{MA})$ & $\begin{array}{l}\text { Péssima representatividade para média aritmética }(\overline{\mathrm{x}}) \\
\text { como medida de posição. }\end{array}$ \\
\hline
\end{tabular}


Assim, o Quadro 3, mostra que a representatividade da média $\operatorname{aritmética}(\bar{x})$, da dimensão descrita por 4 (quatro) parâmetros é inversamente proporcional ao nível de variabilidade, dado pelo $C V$. Após as análises dos parâmetros da dimensão estrutura de trabalho, das unidades produtivas UP1 e UP2, realizou-se as análises gerais da dimensão, denominados resultados médios, cujas construções obtidas a partir da média aritmética dos seguintes termos: média $(\bar{x})$, desvio-padrão $(s)$ e coeficiente de variação $(C V)$, donde serão ponderadas de acordo com Quadro . Logo, para os resultados médios serão definidos e utilizados, em na dimensão de PSC estrutura de trabalho por meio das seguintes notações:

$\left\{\begin{array}{l}\overline{\bar{x}}_{i}=\text { média aritmética simples das médias artméticas }\left(\bar{x}_{i}\right) \text { dos parâmetros } \\ \bar{s}_{i}=\text { médias aritmética simples dos desvios padrões dos parâmetros } \\ \overline{C V}_{i}=\text { média aritmética simples dos coeficientes de variação dos parâmetros }\end{array}\right.$
Com $i=1,2$, onde $i=1$ corresponde a unidade UP1 e $i=2$ corresponde a unidade UP2.

Sendo assim, a análise dos resultados da pesquisa compreendeu-se nas interpretações do indicador de PSC, através da dimensão de estrutura do trabalho, mais especificamente nos parâmetros, assim descritos.

\section{RESULTADOS E DISCUSSÃO}

\section{Análise da Dimensão Estrutura do Trabalho}

A dimensão estrutura de Trabalho da pesquisa de PSC nas unidades produtivas (UP's - UP1 e UP2) de cotonicultura representaram-se a partir das respostas dos pesquisados (colaboradores e gestores), acerca dos parâmetros alimentação, acomodação, qualidade de vida e a participação na decisão, conforme Figura 2.

Figura 2. Análise da Estrutura de Trabalho da Cotonicultura - UP1 e UP2

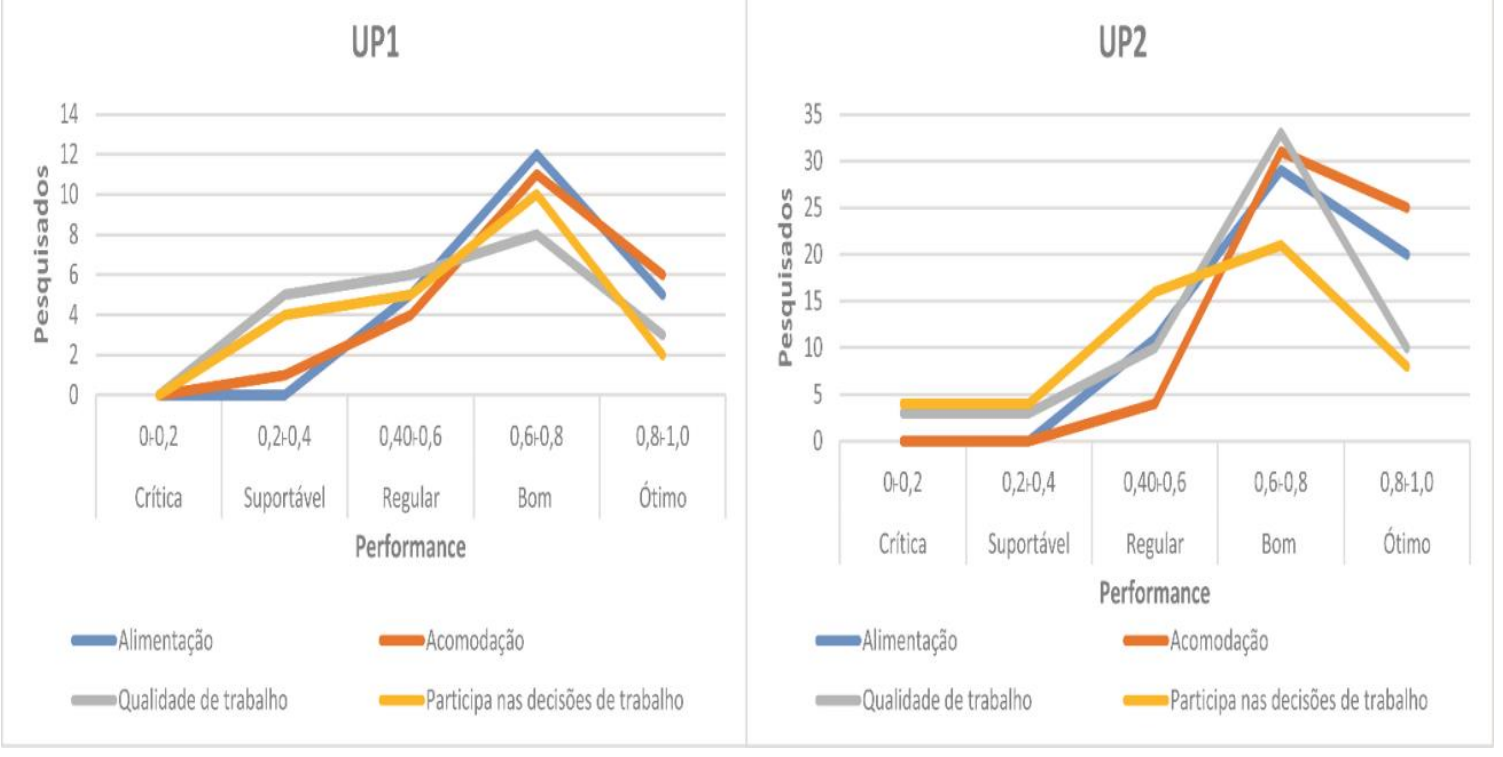

A partir desta coleta, seguir-se-á a análise coletiva, desta dimensão estrutura de trabalho, disposta na Figura 2, para as UP's, a fim de estudar os comportamentos globais de cada parâmetro e o comportamento global da dimensão, acerca das medidas de tendência central e das variabilidades dos dados em relação ao termo médio, dada à sua importância, conforme Tabela 1.

Tabela 1 - Resultado da dimensão de PSC - Estrutura do Trabalho

\begin{tabular}{|c|c|c|c|c|c|c|c|c|c|c|c|c|}
\hline \multicolumn{13}{|c|}{ Dimensão Estrutural $-Q S_{a}$} \\
\hline \multirow{2}{*}{$\begin{array}{c}\text { Unidades produtivas } \\
\text { Parâmetros }\end{array}$} & \multicolumn{6}{|c|}{ UP1 } & \multicolumn{6}{|c|}{ UP2 } \\
\hline & \multicolumn{2}{|c|}{$\bar{x}_{1}$} & \multicolumn{2}{|c|}{$s_{1}$} & \multicolumn{2}{|c|}{$C V_{1}$} & \multicolumn{2}{|c|}{$\bar{x}_{2}$} & \multicolumn{2}{|c|}{$S_{2}$} & \multicolumn{2}{|c|}{$C V_{2}$} \\
\hline$Q S_{a 1}-$ Alimentação & 0,70 & B & 0,14 & B & 0,20 & $\mathrm{~A}$ & 0,73 & B & 0,15 & $\mathrm{~B}$ & 0,19 & $\mathrm{M}$ \\
\hline$Q S_{a 2}-$ Acomodação & 0,70 & B & 0,17 & M & 0,23 & A & 0,77 & B & 0,13 & B & 0,16 & M \\
\hline$Q S_{a 3}$ - Qualidade do trabalho & 0,58 & $\mathrm{R}$ & 0,21 & M & 0,35 & MA & 0,65 & B & 0,20 & A & 0,30 & MA \\
\hline $\begin{array}{l}Q S_{a 4} \text {-Participa das decisões de } \\
\text { trabalho }\end{array}$ & 0,60 & $\mathrm{~B}$ & 0,18 & M & 0,31 & MA & 0,59 & $\mathrm{R}$ & 0,22 & A & 0,37 & MA \\
\hline Resultado Médio de PSC & 0,64 & B & 0,17 & M & 0,28 & A & 0,69 & B & 0,18 & $\mathrm{M}$ & 0,26 & A \\
\hline
\end{tabular}

Legenda: Média: $\bar{x}_{i}(i=1,2)-(\mathrm{C})$ Crítico; (S) Suportável; (R) regular; (B) Boa; (O) Ótima.

Desvio-Padrão e Coeficiente de Variação: $S_{i} ; C V_{i} \quad(i=1,2)-(\mathrm{B})$ Baixa; (M) média; (A) Alta; (MA) Muito Alta

Fonte: elaborado a partir da pesquisa, 2015.

Para as análises dos resultados médios das médias "estrutura de trabalho", dos desvios-padrões e dos coeficientes de variações dos parâmetros, na UP1, têm-se, respectivamente: $\quad \overline{\bar{x}}_{1}=0,64$, com nível de boa (B) performance, $\bar{s}_{1}=0,17$, com média dispersão, $\overline{C V}_{1}=0,28$, e alta variabilidade. Por outro lado, na UP2, têm-se: $\overline{\bar{x}}_{2}=0,69$, com nível de boa (B) performance, $\bar{s}_{2}=0,18$, média dispersão e $\overline{C V}_{2}=0,26$, e alta variabilidade. Quanto a 
representatividade das médias as UP's apresentaram regulares representatividades das médias nas respostas dos pesquisados. Demonstrando assim, que as médias estão tendendo para homogeneidades em relação aos resultados médios da estrutura do trabalho nas UP's. Logo, faz-se necessário, as corporações avaliarem seus impactos e processos dos stakeholders em face da responsividade social corporativa dos resultados produzidos, monitorados, avaliados, compensados (WOOD, 1991). Esses processos derivam da qualidade atribuída aos stakeholders a partir oferta dos proprietários das fazendas. Esses impactos e processos do ponto de vista de Chen et al. (2008), referem-se as competências essenciais atribuídas pela consciência socioambiental dos responsáveis por meio do aprendizado coletivo e das capacidades de inovação dos stakeholders.

No parâmetro: $\bar{x}_{1}=0,70$, com nível de boa (B) performance, $s_{1}=0,14$, baixa dispersão e $C V_{1}=0,20$, e alta variabilidade. Assim, este último resultado, submete-se a um nível regular de aceitabilidade da média $\left(\bar{x}_{1}\right)$, conforme Quadro . Na UP2, confere-se: $\bar{x}_{2}=0,73$, com nível de boa (B) performance, $s_{2}=0,15$, média dispersão e $C V_{2}=0,19$, com média variabilidade, conferindo uma boa representatividade da média. Portanto, as respostas dos entrevistados, em ambas UP's, tiveram boas representatividades nas médias das respostas, o que confere uma avaliação extremamente positiva para esse parâmetro.

Nesse parâmetro, as UP's oferecem áreas de convivências, com todo suporte necessário para as integrações dos funcionários em suas estruturas compatíveis às exigidas pelas normas regulamentadoras NR 31 (BRASIL, 2013), no item 31.23, como: refeitórios, lavanderias, instalações sanitárias na sede, com conservação e higiene, pisos de cimentos, com toda infraestrutura necessária em consonância com esta legislação. $\mathrm{O}$ atendimento das exigências em consonância os padrões legais, de acordo com Brammer et al. (2013) trata-se da RSC como estímulo às transformações sociais que cercam seus exercícios éticos, respeitando as pessoas. A organização dos refeitórios das UP's está estruturada conforme a NR 31, no item 31.23, que regulamenta as áreas dos refeitórios com mesas, cadeiras, ambientes climatizados, amplos, arejados para aos trabalhadores se alimentarem com qualidade e higiene. Esses ambientes são projetados com cozinhas industriais distribuindo refeições (café da manhã, almoço, café da tarde e jantar), gratuitamente, para os funcionários e suas famílias. A água utilizada para o preparo da alimentação e consumo são tratadas e também distribuídas para as residências dos funcionários.

Nas informações in loco, notou-se que, as estruturas dos refeitórios, na UP1, têm espaço em relação ao número de trabalhadores da fazenda, dessa forma, para os trabalhadores do campo as refeições são distribuídas próximas aos locais de trabalho. No tocante a isso, as respostas dos pesquisados as refeições são entregues em marmitas e com qualidade, próximos às localidades de produção e com pausa no horário para o descanso diário.

$\mathrm{Na}$ UP2, tem amplo refeitório totalmente projetada para acomodação dos trabalhadores no momento da alimentação, com higiene e qualidade na alimentação. Neste ambiente percebe-se a satisfação por terem um espaço amplo, planejado e com alimentação de qualidade nas refeições. Na percepção de Waddock et al. (2002), as estratégias de benefícios aos stakeholders no que tange ao conjunto das práticas de gestão garantem a maximização dos impactos positivos nas operações, na sociedade de forma legal, ética e comercial, como as expectativas da sociedade.

Nesse sentido, houve coerência entre as respostas dos pesquisados, quanto a alimentação das unidades produtivas, cabendo destacar os seguintes depoimentos, conforme Quadro 4.

Quadro 4. Depoimentos dos pesquisados das UP's de Cotonicultura - UP1 e UP2

UP1:

$\mathrm{P}_{1}$ : "a alimentação de qualidade e o ambiente é adequado e totalmente climatizada para realizar as refeições".

$\mathrm{P}_{2}$ : “A alimentação é igual para todos não havendo discriminação do tipo de trabalho que realiza".

\section{UP2:}

$\mathrm{P}_{1}$ : "A comida é de qualidade, bem quente e gostosa".

$\mathrm{P}_{4}$ : "A alimentação de qualidade e entregue na hora certa".

$\mathrm{P}_{6}$ : "A comida pode ser melhorada".

Legenda: UP'S: Unidades Produtivas; UP1: Unidade Produtiva 1; UP2: Unidade Produtiva 2 e P: pesquisados.

Fonte: elaborado pelos pesquisadores, a partir da pesquisa, 2015.

De acordo com as respostas dos pesquisados, o parâmetro acomodação, na UP1, as análises das médias, dos desvios-padrões e coeficientes de variações, corresponderamse, respectivamente: $\bar{x}_{1}=0,70$, com nível de boa (B) performance, $s_{1}=0,17$, média dispersão e $C V_{1}=0,23$, com alta representatividade nas respostas. Assim, este resultado, consistiu em um nível regular de aceitabilidade da média $\left(\bar{x}_{1}\right)$, conforme Quadro . Na UP2, caracterizou-se, $\bar{x}_{2}=$ 0,77 , com nível de boa (B) performance, $s_{2}=0,13$, com baixa dispersão e $C V_{2}=0,16$, com boa variabilidade, conferindo uma boa representatividade da média. Logo, em ambas as UP's, esse parâmetro considerou-se uma análise positiva da média e serviu como medida avaliativa.

Desse modo, as UP's oferecem, casas para as famílias e alojamentos separados por sexo, ambos, totalmente climatizados e sem ônus, no entanto, disseram que ainda faltam moradias para as famílias. Nessa condição, a NR 31, no item 31.21.10, diz que as edificações visam promover segurança e saúde para o trabalhador e distanciar das aglomerações de pessoas. Ainda, a NR 31 (BRASIL, 2013), no item 31.23.11 refere-se as moradias devem prover a) capacidade dimensionada para uma família; b) paredes construídas em alvenaria ou madeira; c) pisos de material resistente e lavável; d) condições sanitárias adequadas; e) ventilação e iluminação suficientes; f) cobertura capaz de proporcionar proteção contra intempéries; g) poço ou caixa de água protegido contra contaminação; h) fossas sépticas, quando não houver rede de esgoto, afastadas da casa e do poço de água, em lugar livre de enchente e a jusante do poço.

Além disso, no item 31.23.11.2, da NR 31 (BRASIL, 2013), essas moradias familiares devem ser construídas em local arejado e afastadas, no mínimo, cinquenta metros das construções destinadas a outros fins. Nesse sentido, todas as edificações das UP’s são oferecidas pelos proprietários e equiparados contemplam as normas reguladoras, são elas: residências, escritórios, refeitórios, silos, depósitos de armazenamento e descontaminadores, bem como também próximas as lavouras de algodão para agilizar o processo logístico. Dessa maneira, essas ações puderam ser 
averiguadas nas avaliações dos pesquisados, com base na Quadro 5

Quadro 5. Depoimentos dos pesquisados das UP's de Cotonicultura - UP1 e UP2

\section{UP1:}

$\mathrm{P}_{1,8}$ : “As casas de moradia são para poucos".

$\mathrm{P}_{2,3}$ : Os alojamentos têm ar condicionado, chuveiro quente e preparados para dormir".

$\mathrm{P}_{12}$ : "Ainda falta alojamento e mais casas para morar".

$\mathrm{P}_{4,6}$ : "As casas são organizadas e com ar condicionado".

\section{UP2:}

$\mathrm{P}_{1}$ : "Faltam mais moradias para os funcionários".

$\mathrm{P}_{2,3}$ : "Muitos trabalhadores gostariam de trazer suas famílias para morar no trabalho, mas não tem casa para todos".

$\mathrm{P}_{16}$ : "Os alojamentos têm ar condicionado".

$\mathrm{P}_{28}$ : "As casas são organizadas e com ar condicionado e chuveiro elétrico".

$\mathrm{P}_{38}$ : "Faltam mais moradias para as famílias".

$\mathrm{P}_{6}$ : "Alojamento com ar condicionado, chuveiro elétrico e sala de TV".

Legenda: UP'S: Unidades Produtivas; UP1: Unidade Produtiva 1; UP2:

Unidade Produtiva 2 e P: pesquisados.

Fonte: elaborado pelos pesquisadores, a partir da pesquisa, 2015

No parâmetro qualidade de vida no trabalho, na UP1, as análises das médias, dos desvios-padrões e os coeficientes de variações, compreenderam-se, respectivamente: $\bar{x}_{1}=0,58$, com nível de regular (R) performance, $s_{1}=0,21$, com média dispersão e $C V_{1}=0,35$, com muito alta variabilidade. Dessa forma, a média $\left(\bar{x}_{1}\right)$ possui péssima representatividade, conforme Quadro 27, conferindo que as respostas dos pesquisados se comportam de maneira heterogênea. Na UP2, caracterizou-se, $\quad \bar{x}_{2}=0,65$, com nível de boa (B) performance, $s_{2}=0,20$, com média dispersão e $C V_{2}=0,30$, com alta variabilidade, atribuindo uma regular (R) representatividade da média $\left(\bar{x}_{2}\right)$, sendo assim, conclui-se péssimas homogeneidades das médias $\left(\bar{x}_{1}\right.$ e $\left.\bar{x}_{2}\right)$,) nas respostas dos pesquisados.

No que concerne à qualidade do trabalho, os empregadores rurais ou equiparados devem promover aos stakeholders, condições de trabalho, como suportes fisiológicos, de modo a suprir suas necessidades básicas, como acomodações de moradias/alojamentos e refeitórios. Outrossim, devem preservar a segurança e saúde do trabalhador como um fator decisivo para preservar a integridade do trabalhador, como mostrado na NR 31 (BRASIL, 2013), 31.3.3, no item C. No entendimento de Wood (2010) a PSC nas interações corporativas com ambiente mais amplo devem incluir o desenvolvimento social, cultural, legal, político e econômico como respostas sociais de RSC nos processos corporativos.

Acerca disso, para melhorar qualidade do trabalho, as UP's implantaram ações como as escalas de horários de trabalho e intervalos de descansos controlados pelos relógios eletrônicos de pontos, com informativos indexados para facilitar a disseminação da informação ente os trabalhadores. Quanto aos banheiros nas sedes todos estão adequados às normativas, contudo, não se visualizou os banheiros nos locais de plantações. Segundo a pesquisa, os três primeiros parâmetros demonstraram-se satisfatórios, entretanto, quando se relacionou os banheiros existentes nas plantações, os colaboradores não responderam esse quesito, além disso, não foram localizados nas propriedades banheiros químicos.

Quando se perguntou sobre a qualidade do trabalho os trabalhadores relataram que, na UP1, as práticas laborais são degradantes e cansativas e se tivessem oportunidades mudariam de profissão, uma vez que ficam expostos ao sol e têm contato com materiais e substâncias perigosas. Outros, contudo, acreditam que foi uma excelente oportunidade trabalhar nessa organização. Na UP2, de acordo com os pesquisados, grande parte deles, estão insatisfeitos, por considerarem o trabalho degradante e cansativo e que permanecem na fazenda devido à falta de oportunidades nas cidades. Com base nisso as respostas estão descritas na Quadro 6.

Quadro 6. Depoimentos dos pesquisados das UP's de Cotonicultura - UP1 e UP2

\section{$\mathrm{P}_{1}$ : "Esse trabalho é cansativo".}

$\mathrm{P}_{2,4}$ : "Somos obrigados a morar longe da família e temos muitos trabalhos braçal e que é obrigado a ficar debaixo do sol".

$\mathrm{P}_{3,9}$ : "É limitado a visita na cidade".

$\mathrm{P}_{1,3,5}$ : "Lugar bom para viver com a família".

$\mathrm{P}_{5,8}$ : "Temos moradia com água, luz e lazer para família".

$\mathrm{P}_{8}$ : "Trabalho desgastante".

$\mathrm{P}_{18}$ : "Se tivesse outra oportunidade não estaria aqui, infelizmente tempo pouco estudo para morar na cidade".

Legenda: UP'S: Unidades Produtivas; UP1: Unidade Produtiva 1; UP2: Unidade Produtiva 2 e P: pesquisados.

Fonte: elaborado pelos pesquisadores, a partir da pesquisa, 2015.

No parâmetro participação nas decisões de trabalho, na UP1, as análises das médias, dos desvios-padrões e coeficientes de variações, compreendem-se, respectivamente: $\bar{x}_{1}=0,60$, com nível de boa (B) performance, $s_{1}=0,18$, com média dispersão e $C V_{1}=0,31$, com muito alta (MA) representatividade na média. Assim, seu resultado, correspondeu-se a péssima de representatividade da média $\left(\bar{x}_{1}\right)$, conforme Quadro . Na UP2, apresentou-se: $\bar{x}_{2}=0,59$, com nível de regular (R) performance, $s_{2}=0,22$, com média dispersão e $C V_{2}=0,37$, com muito alta (MA) variabilidade, conferindo uma péssima representatividade da média. Assim, em ambas UP's, temos médias $\left(\bar{x}_{i}\right)$ nos limites de transição dos níveis de performance entre regular e boa, porém com péssimas representatividades, o que traduz, no geral, que esse parâmetro teve um nível negativo de avaliação, dando uma correspondência não homogênea entre as respostas dos entrevistados.

Nesse parâmetro nas UP's, nas avaliações in loco os pesquisados abordaram que estão descontentes, por não poderem contribuir nas decisões nas UP's. Dessa forma, na UP1, percebeu-se relações são mais formais entre os gestores e colaboradores, entretanto há mais abertura para colocarem suas opiniões. Godard (2002) salienta que a RSC depende das modalidades técnicas de explorações e decisões para as premissas de sustentabilidade, com as atividades corporativas com justiça social, justiça ambiental e equidade para todos os trabalhadores envolvidos. No tocante a isso, Kang (2012) ressalta que os gestores devem inserir na conduta ética em uma declaração de valor seguido por todos os stakeholders, tendo em vista o compromisso social e moral correto (orientação ética). Enquanto, na UP2, os pesquisados 
mencionaram que participam nas decisões para definição de ações de melhoria cotidiana da unidade e das vivencias locais. De tal modo, apontadas nas respostas dos pesquisados no Quadro 7.

Quadro 7. Depoimentos dos pesquisados das UP's de Cotonicultura - UP1 e UP2

\begin{tabular}{l}
\hline \multicolumn{1}{|c|}{ UP1: } \\
\hline $\mathrm{P}_{1}$ : "Somos mandados a trabalhar". \\
$\mathrm{P}_{2}$ : "Posso contribuir com as ideias da minha área. \\
$\mathrm{P}_{3}$ : "Tenho liberdade para decidir as ações na fazenda e \\
buscar melhoria para ela". \\
\hline \multicolumn{1}{|c|}{ UP2: } \\
\hline $\mathrm{P}_{1}$ : "Ajudo melhorar com ideias". \\
$\mathrm{P}_{3}$ : "Dou ideia para melhorar o ambiente de trabalho e discuto \\
com os colegas". \\
$\mathrm{P}_{10}$ : "Estou aqui para obedecer as ordens". \\
Legenda: UP'S: Unidades Produtivas; UP1: Unidade Produtiva 1; UP2: \\
Unidade Produtiva 2 e P: pesquisados. \\
Fonte: elaborado pelos pesquisadores, a partir da pesquisa, 2015.
\end{tabular}

Assim, os resultados da dimensão estrutura do trabalho das UP1 e UP2, estão representadas de acordo com seus parâmetros, das médias, dos tipos de classificações de PSC e das representatividades das médias de acordo com as respostas dos pesquisados, com base no Tabela 3 .

De acordo com o Tabela 3, em ambas UP's, observamse nos resultados médios das médias $\left(\overline{\bar{x}}_{i}\right)$ níveis de performances boas (B), conforme Quadro 1, porém, com $C V$ 's (coeficientes de variações) com níveis altos de variabilidade (A), dando correspondências regulares às médias $\left(\overline{\bar{x}}_{i}\right)$, quanto às suas representatividades, conforme Quadro Assim, conclui-se que as respostas dos pesquisados não apresentaram homogeneidades em alguns parâmetros da dimensão considerada, como por exemplos, nos parâmetros: qualidade de vida no trabalho e a participação nas decisões de trabalho.

Tabela 3. Resultado de PSC da dimensão estrutura do trabalho- $Q S_{a}$

\begin{tabular}{|c|c|c|c|c|c|c|}
\hline \multirow{2}{*}{$\begin{array}{r}\text { Unidades Produtivas } \\
\text { Parâmetros }\end{array}$} & \multicolumn{3}{|c|}{ UP1 } & \multicolumn{3}{|c|}{ UP2 } \\
\hline & Média & Classificação & $\begin{array}{l}\text { Representatividade } \\
\text { da Média }\end{array}$ & Média & Classificação & $\begin{array}{c}\text { Representatividade } \\
\text { da Média }\end{array}$ \\
\hline$Q S_{a 1}-$ Alimentação & 0,70 & Boa & Regular & 0,73 & Boa & Média \\
\hline$Q S_{a 2}$ - Acomodação & 0,70 & Boa & Regular & 0,77 & Boa & Boa \\
\hline$Q S_{a 3}$ - Qualidade do trabalho & 0,58 & Regular & Péssima & 0,65 & Boa & Regular \\
\hline $\begin{array}{l}Q S_{a 4} \text { - Participa das decisões } \\
\text { de trabalho }\end{array}$ & 0,60 & Boa & Péssima & 0,59 & Regular & Péssima \\
\hline Resultado Médio & 0,64 & Boa & Regular & $\mathbf{0 , 6 9}$ & Boa & Regular \\
\hline
\end{tabular}

Fonte: elaborado a partir da pesquisa, 2015.

Na dimensão estrutura do trabalho ficou descrita como boa performance e, em referência aos parâmetros das UP1 e UP2, na alimentação e acomodação apresentaram boas performances, sendo a alimentação com mais representatividade nas respostas dos pesquisados. No parâmetro qualidade de vida no trabalho caracterizou-se, nas UP's, com níveis regulares e boas performances, respectivamente. No parâmetro participação das decisões de trabalho, as UP's cercaram-se com boas e regulares performances, no entanto, ambas as UP's, apontaram péssimas representatividades nas médias das respostas dos pesquisados. Ademais, os parâmetros alimentação e acomodação apresentaram-se além dos padrões exigidos por leis, bem como pelas normas regulamentadoras, uma vez que oferecem de acordo com as respostas dos pesquisados as instalações das acomodações, uma vez que em ambas as UP's são climatizadas com ar condicionado e televisões.

No parâmetro qualidade do trabalho, as estruturas de trabalho das UP's correspondem em média as expectativas dos trabalhadores. No que tange a qualidade do trabalho em relação aos esforços de atividades realizadas pelos trabalhadores informaram que o trabalhado é desgastante e cansativos na produção de algodão, onde muitos trabalhadores mencionaram que se tivessem oportunidades mudariam de emprego.

Em consonância, às decisões de trabalho percebeu-se principalmente na UP2, alta sinergia entre os gestores, bem como entre os colaboradores e gestores, entretanto, podendo ainda ser melhorada com reuniões integrações para sensibilizar e motivar os trabalhadores na proposição de novas práticas aliadas as condições sociais, legais e de segurança.

\section{CONCLUSÕES}

Os resultados apontados pelos pesquisados das duas unidades produtivas de cotonicultura apresentaram em consonância com a médias das médias $\left(\overline{\bar{x}}_{i}\right)$ das dimensões dos níveis de PSC da dimensão estrutura de trabalho, níveis classificações com performances boas (B), contudo, tiveram altos de variabilidades nas médias das respostas dos pesquisados, dando correspondências regulares às médias $\left(\overline{\bar{x}}_{i}\right)$.

Os parâmetros alimentação e acomodação em ambas as UP's apresentaram maiores representatividades das médias em relação as respostas dos pesquisados, resultando assim, em boas performances, no entanto com regulares e boas representatividades nas médias das respostas dos pesquisados. Ademais, estas condições reforçaram-se devido aos padrões estruturados pelos UP'S, que oferecem além dos padrões exigidos pelas leis e as normas regulamentadoras, como por exemplo: as alimentações e acomodações são de qualidade e em ambas as UP's são climatizadas com ar condicionado e televisões.

No que se refere aos os parâmetros de qualidade do trabalho e participação nas decisões de trabalho, nas UP's houveram algumas variações em relação as respostas dos pesquisados apresentaram, regulares e boas performances, respectivamente. Por fim, ao parâmetro participação nas decisões de trabalho nas UP's apontaram, boas e regulares 
performances, respectivamente. De tal modo, nas UP's, estes parâmetros tiveram péssimas representatividades nas médias das respostas dos pesquisados, apesar das UP's oferecerem suportes necessários na produção de algodão em conformidade com as normas de segurança do trabalho e as legislações trabalhistas conforme estabelecidos nos princípios ABR e BCI.

\section{REFERÊNCIAS}

ABRAPA. Associação Brasileira dos Produtores de Algodão, 2014. O algodão no Brasil. Disponível: http://www.abrapa.com.br/estatisticas/paginas/algodao-nobrasil.aspx. Acesso: 25 ago. 2014

ABRAPA. Associação Brasileira dos Produtores de Algodão. Defensivos agrícolas: como evitar dados a saúde e o meio ambiente. Série 2008. Disponível em: http://www.ipam.org.br/biblioteca/livro/Defensivos-agricolasComo-evitar-danos-a-saude-e-ao-meio-ambiente/681 Acesso em: 26 out. 2015 .

ABRAPA. Associação Brasileira dos Produtores de Algodão. Guia de orientação: algodão brasileiro responsável do Programa Brasileiro Responsável 2008 Disponível: www.abrapa.com.br/biblioteca/documents/guia_abrapa_net.p df. Acesso: 25 agosto de 2015.

AZEVEDO, Carlos Eduardo Franco; OLIVEIRA, Leonel Gois Lima; GONZALEZ, KURAMOTO Rafael; ABDALLA Márcio Moutinho. A Estratégia de Triangulação: Objetivos, Possibilidades, Limitações e Proximidades com o Pragmatismo. Encontro de Ensino e Pesquisa em Administração e Contabilidade. Brasília/DF- 3 a 5 novembro, 2013.

BOUlOUTA, I.; PITELIS, C.N. Who Needs CSR? The Impact of Corporate Social Responsibility on National Competitiveness. Journal of business ethics, v.119, n.3, p.349-364, 2014.

BRAMMER, S.; JACKSON, G.; MATTEN, D. Corporate Social Responsibility and institutional theory: new perspectives on private governance. Socio-Economic Review, v.10, n.1, p. 3-28, 2013.

BRASIL. LEI DO TRABALHADOR RURAL. Estatuto e normas reguladoras do trabalho rural - NR 31, 2013. Disponível:

http://www.planalto.gov.br/ccivil_03/LEIS/L5889.htm.

Extraído em 24/09/2015.

CARROLL, A.B. A three-dimensional conceptual model of corporate performance. Academy of Management Review, v.4, n.4, p.497-505, 1979.

CHEN, Y.S.; CHANG, C.H.; WU, F.S. Origins of green innovations: the differences between proactive and reactive green innovations. Management Decision, v.50, n.2, p.368398, 2008.

COX, J. W.; HASSARD. J. Triangulation in Organizational Research: a Representation in Organization. AB/INFORM Global, v.12, n.1, p.109-133, 2005.
DAVIS, K.; BLOMSTROM, R. L. Business and its environment. McGraw-Hill, New York, 1966.

DAHLSRUD, A. How corporate social responsibility is defined: an analysis of 37 definitions. Corporate social responsibility and environmental management, v.15, n.1, p.113, 2008.

DENZIN, N. The research act: a theoretical introduction to sociological methods. (2a ed). New York: Mc Graw-Hill, (1978).

DUFFY, M. E. Methodological triangulation: a vehicle for merging quantitative and qualitative research methods. Journal of Nursing Scholarship, v.19 n.3, p. 130-133, 1987.

GODARD, O. A gestão integrada dos recursos naturais e do meio ambiente: conceitos, instituições e desafios de legitimação In: VIEIRA, Paulo Freire e WEBER, Jaques. Gestão de Recursos Naturais Renováveis e Desenvolvimento: Novos Desafios para a Pesquisa Ambiental. São Paulo: Cortez, 2002.

HILL, R., T. Ainscough, T. Shank e D. Manullang (2006), Corporate Social Responsibility and Socially Responsible Investing: A Global Perspective. Journal of Business Ethics, v. 70, p.165-174.

HUTCHINS, M.J., SUTHERLAND, J.W. An exploration of measures of social sustainability and their application to supply chain decisions. Journal of Cleaner Production, v.16, n.15, p.1688-1698, 2008.

IBGE. Produção Agrícola 2013: Sistema do IBGE de Recuperação Automática Sidra: http://www.sidra.ibge.gov.br/bda/tabela/protabl.asp?c=1612\& $\mathrm{z}=\mathrm{p} \& \mathrm{o}=18 \& \mathrm{i}=\mathrm{p}$. Acesso em: 16 de ago 2015.

INSTITUTO ETHOS. Indicadores de Sustentabilidade. Disponível: HTTP://WWW3.ETHOS.ORG.BR/. Acesso em 04 de jul. 2014.

JACOBI, P.; JUNIOR, R.M.A. (orgs.). Consumo e sustentabilidade. In: Desafios do consumo. Petrópolis, RJ: Vozes, 2007.

KANG, N.; MOON, J. Institutional complementarity between corporate governance and corporate social responsibility: a comparative institutional analysis of three capitalisms. SocioEconomic Review, v.10, n.1, p.85-108, 2012.

MARTINS, Gilberto de Andrade; DOMINGUES, Osmar. Estatística Geral e Aplicada. 5 ed. Revista Ampliada. São Paulo: Editora Atlas, 2014.

MATOS FILHO, A.M. Agricultura orgânica sob a perspectiva da sustentabilidade. Florianópolis-SC. Dissertação (Mestrado em Engenharia Ambiental) Universidade Federal de Santa Catarina, 2004.

MATHISON, S. Why triangulate? Educational Researcher, v. 13, p.13-17, 1988. 
MCGUIRE, J. Business and society. New York: MgGrawHill 1963.

MINAYO, M. C. S. Hermenêutica-Dialética como caminho do pensamento social. In: MINAYO, Maria Cecília de Souza; DESLANDES, Suely (Org.) Caminhos do pensamento: epistemologia e método. Rio de Janeiro: Fiocruz, 2002.

Norma Regulamentadora de Segurança e Saúde no trabalho da Agricultura, Pecuária, Silvicultura, Exploração Florestal e Equicultura - NR 31. Disponível em: <http://mtegov.br/legislação-normas_regulamentadoras nr_31.pdf>. Acesso em 15 de nov. de 2015.

WADDOCK, Sandra A.; BODWEL, Charles 1, Graves, YIN, Robert K. Estudo de caso: planejamento e métodos.

Samuel B. Responsibility: The new business imperative. 4.ed. Porto Alegre: Bookman, 2010.
Academy of Management Executive, v.16, n.2, p. 132-148, 2002.

World Business Council for Sustainable Development (Corporate Social Responsibility, Meeting Changing Expectations, WBCSD Publications, 1998. ISBN 2-94-024003-5.

WOOD, D. J. Corporate social performance revisited. Academy of Management, v.16, n.4, p.691-718, 1991.

WOOD, D.J. Measuring corporate social performance: a review. International. Journal of Management Reviews, v.12, n. 1, p. $50-84,2010$. 